\title{
Consumer Attitude and Awareness Regarding Use of Anti-Ulcerant Drugs in Bangladesh
}

\author{
Hasina Akter ${ }^{1}$, Md. Zubayer Ibna Khan², Md Aminul Islam³ ${ }^{3}$ Bithika Mali1 ${ }^{1}$ S M Yasir Arafat ${ }^{4 *}$ \\ ${ }^{1}$ Department of Graduate Nursing, Bangabandhu Sheikh Mujib Medical University, Bangladesh \\ 2Department of Public Health, North South University, Dhaka, Bangladesh \\ ${ }^{3}$ Department of Media Studies and Journalism, University of Liberal Arts Bangladesh, Dhaka, Bangladesh \\ ${ }^{4}$ Department of Psychiatry, CARe Medical College, Dhaka, Bangladesh
}

\section{*Corresponding Author}

S M Yasir Arafat

\section{Article History}

Received: 06.07.2019

Accepted: 24.07.2019

Published: 30.07 .2019

\begin{abstract}
Background: Anti-ulcerents drugs are a class of drugs has been using to treat ulcers in the stomach and the upper part of the small intestine. Although, anti-ulcerants are beneficial in many cases, adverse effects have not gone unnoticed. Objective: We aimed to find out the anti-ulcerant use scenario in Bangladesh and consumers' attitude and awareness regarding the long term use of anti-ulcerants. Methods: This was a hospital-based cross-sectional study where 103 respondents were interviewed through convincing sampling technique. Respondents were indoor admitted patients of Bangabandhu Sheikh Mujib Medical University (BSMMU), Dhaka. A questionnaire consisting 24 questions in total was developed to interview the participants. Collected data was analyzed by Statistical Package for the Social Sciences (SPSS) software. Results: Among 103 respondents, $50.5 \%$ were male 88 were taking anti-ulcerants $43(41.7 \%)$ were taking medication per advice of physicians. About $63 \%$ participants are willing to continue their drugs. Conclusion: Evidence based practice during prescribing the antiulcerants in necessary. Consumers should make aware its side effects as well as effects of long term use of antiulcerants.
\end{abstract}

Keywords: Anti-ulcerents, drugs, Bangladesh

\section{INTRODUCTION}

Anti-ulcerants drugs are a class of drugs has been using to treat ulcers in the stomach and the upper part of the small intestine. Anti-ulcerants like Proton pump inhibitors (PPIs) inhibit the activity of pumps transporting hydrogen ions across cell membranes and are used to inhibit gastric acid secretion. It causes profound suppression of acid secretion; therefore it is used to treat gastric-associated diseases globally [1]. Its efficacy has been proved in the treatment of gastro-esophageal reflux disease (GERD), peptic ulcers and dyspepsia [2-5].

Although, anti-ulcerants relieve us from the symptoms of gastric-associated diseases, its side-effects have not gone unnoticed [1-5]. A recent study has shown that chronic ingestion of anti-ulcerants likePPIs can reduce estimated glomerular filtration rate (eGFR) in ambulatory older adults [6]. A meta-analysis has shown that acute stroke patients taking Acid-suppressive medications namely PPIs have a higher risk of being effected to Hospital-acquired pneumonia [7]. Also, PPI does not prevent the formation of anastomotic strictures [8]. Diseases like acute interstitial nephritis and pseudomembranous colitis are also consequences of prolonged use of PPI [9]. Keeping aspects of all the side-effects despites its relatively safe uses, a guideline for anti-ulcerants use is rudimentary. The National Institute for Health and Clinical Excellence (NICE) has published such sort of guideline back in 2000 [10]. The prescription PPIs without clear indication and prolonged period than recommendation have appeared to be frequent [11].

As Bangladesh is a growing economic country where pharmaceutical business is blooming day by day. Pharmaceutical industry is one of the progressive and perspective industries in Bangladesh. It contributes $1 \%$ to the country's GDP and is the third largest industry in terms of contribution to government revenue [12-17]. Anti-ulcerants are significantly dominating the huge volume sells with marked impact on company revenue. IMS 2016 shows anti-ulcerants as therapeutic class tops the whole market possessing $15 \%$ of total market share. This statistics is a testimony of huge PPI consumption in our country. Yet we still do not have clear idea whether this huge amount of PPI use is rational and per appropriate recommendation. The cost effectiveness of anti-ulcerants is also

Copyright @ 2019: This is an open-access article distributed under the terms of the Creative Commons Attribution license which permits unrestricted use, distribution, and reproduction in any medium for non commercial use (NonCommercial, or CC-BY-NC) provided the original author and source are credited. 
unclear as low price of brands are relatively less sensitive to doctors $[12,13]$. In this study, we aim to find out the anti-ulcerant use scenario in Bangladesh and consumers' attitude and awareness regarding the long term use of anti-ulcerants.

\section{METHOD}

This study was a hospital-based cross-sectional study. Through convincing sampling technique, 103 participants were enrolled and interviewed for this study from January to March 2019. According to the inclusion criteria, participants were indoor admitted patients of Bangabandhu Sheikh Mujib Medical University (BSMMU), Dhaka. A questionnaire consisting 24 questions in total was developed to interview the participants. In the first part of the questionnaire, socio-demographic variables of the participant were explored. This part covered questions like participant's age, gender, religion, marital status, academic qualification, job, family and monthly income. To obtain idea on anti-ulcerant consuming nature, in second part questions were asked for how long they are taking drug, mode of consumption, if they are consuming it at present, the name of the drug, any concomitant drug consumption, who prescribed anti-ulcerant, whether they were aware of the reason behind prescribing this anti-ulcerant, for how long they were supposed to take it and if they were advised to follow-up visit. To know the awareness against prolonged use of anti-ulcerant drug, questions were asked whether the participants asked the healthcare provider about the drug, whether they healthcare provider made them aware of the drug and its adverse effect of this particular drug. It was aimed to find out if the participants were willing to continue this medication and if they think they will be able to live well without consuming anti-ulcerant. Collected data was analyzed by Statistical Package for the Social Sciences (SPSS) software.

\section{RESULT}

103 participants were enrolled for this study. Mean age was 36.84 years $(S D=12.923)$. Among them, 5 respondents were taking anti-ulcerant for 13 years. 43 respondents were advised anti-ulcerant by physicians while 13 were taking on their own. 47 respondents knew the disease that led them to taking medicine. However, 23 respondents do not know whether they have to go to physicians for follow-up. Despite that, most of the participants $(n=65)$ are willing to continue their drugs. Most of the respondents $(57$, $55.3 \%$ ) do not believe that modifying lifestyle will change their disease condition.

Table-1: Distribution of demographic variables among the respondents $(n=103)$

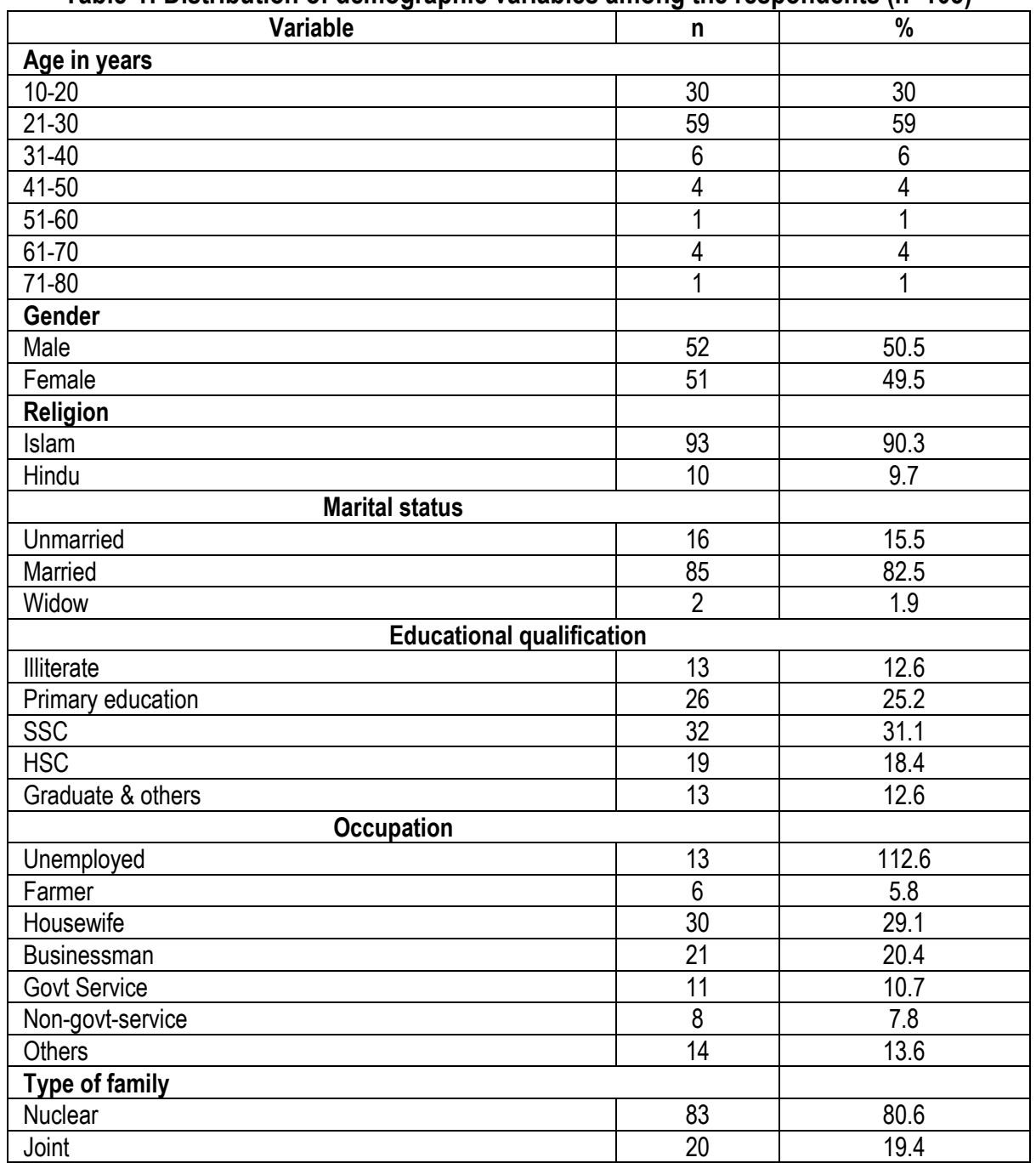


Table-2: Consumption pattern of respondents

\begin{tabular}{|c|c|c|}
\hline Variable & $\mathbf{n}$ & $\%$ \\
\hline \multicolumn{3}{|l|}{ Antiulcerant taking } \\
\hline Yes & 88 & 85.4 \\
\hline No & 15 & 14.6 \\
\hline \multicolumn{3}{|c|}{ Type of consumption } \\
\hline Regular & 43 & 41.75 \\
\hline Irregular & 45 & 43.69 \\
\hline Missing & 15 & 14.56 \\
\hline \multicolumn{3}{|c|}{ Name of the antiulcerant } \\
\hline PPIs & 60 & 58.1 \\
\hline H2 bloker & 21 & 20.4 \\
\hline Analgesic taking & 46 & 44.7 \\
\hline \multicolumn{3}{|c|}{ Whom advice they follow } \\
\hline Self & 13 & 12.6 \\
\hline LMFA & 17 & 16.5 \\
\hline Salesman & 12 & 11.7 \\
\hline Physician & 43 & 41.7 \\
\hline Relatives & 1 & 1 \\
\hline Others & 2 & 1.9 \\
\hline Total & 88 & 85.4 \\
\hline \multicolumn{3}{|c|}{ Want to know of reason } \\
\hline Yes & 24 & 23.3 \\
\hline No & 64 & 62.5 \\
\hline Missing & 15 & 14.6 \\
\hline \multicolumn{3}{|c|}{ Prior awareness } \\
\hline Yes & 18 & 17.5 \\
\hline No & 70 & 68 \\
\hline Missing & 15 & 14.6 \\
\hline \multicolumn{3}{|c|}{ Willing to continue medicine } \\
\hline Yes & 65 & 63.1 \\
\hline No & 22 & 21.4 \\
\hline Missing & 16 & 15.5 \\
\hline \multicolumn{3}{|l|}{ Know side effects } \\
\hline Yes & 26 & 25.2 \\
\hline No & 61 & 59.2 \\
\hline Missing & 16 & 15.5 \\
\hline
\end{tabular}

\section{DISCUSSION}

Proton-pump inhibitors (PPI) is a time-tested drug for effective suppression of gastric acid and is indicated in several upper gastro-intestinal disorders [13]. Diseases like Gastro-esophageal Reflux Disease, peptic ulcer and dyspepsia are treated using antiulcerantslikePPIs $[2-5,13]$. As ulcers can be happened in high-risk patients taking Non-Steroidal Anti-Inflammatory Drugs (NSAIDs) and also patients receiving glucocorticoids for prolonged duration, PPIs are being used as a concomitant treatment [19]. Although, PPIs are beneficial in many cases, adverse effects have not gone unnoticed. Long-term use of PPIs can lead to reduced eGFR, hospital acquired pneumonia, acute interstitial nephritis, pseudomembranous colitis [6-9, 13]. Despite the risk of imminent adverse effects, PPI medication have been experiencing blooming in term of expenditure. In United Kingdom, in term of expenditure, they are the single largest drug group [19]. Germany experienced an annual expenditure of $\$ 1.2$ billion in 2010 and globally the cost was $£ 7$ billion [20]. From different studies, it was found that Bangladesh is not an exception. Recent tradition shows, anti-ulcerants as a therapeutic class tops the whole market with $15 \%$ of the total market share and according to brand-wise ranking based on sales volume, among the 25 available brands, there are 11 anti-ulcerant brands with the top 4 anti-ulcerant brands [21]. It can be therefore said that the consumption of anti-ulcerants are increasing continuously. In this study, we investigated the attitude and consciousness level of the consumers taking anti-ulcerants. Gender was nearly equally distributed among the 103 participants who were mostly middle-aged and married. Omeprazole was taken by the largest cohort and the largest group who were taking this drug was for 5 years. A large group was founded to be housewives. Though the participants were taking it for a prolonged period, they were consuming it irregularly. Reason behind the consumption was largely based on gastric pain and 46 participants were also taking analgesic in addition. However, most of the participants were unaware of the disease they were suffering from though a large number of them were prescribed by the physicians. Most of the participants did not ask about the drug and did not know if they require a follow-up visit. Lack of prior awareness before medication and subsequent adverse effect risk can in long term deteriorate doctorpatient relationship as it has been proven that there is extreme paucity of literatures on doctor-patient relationship in Bangladesh [22] Despite the unawareness ofthe side-effects, a large number of participants were unwilling to give up consuming and willing to continue anti-ulcerants as medication. It is also firm belief of the most respondents, without consumption of anti-ulcerants, it would not be possible to lead a modified, controlled life-style and limit the disease condition. Irrational use of anti-ulcerant consumption can also be 
seen in many parts of the globe. A longitudinal analytic study on inpatient care with inpatient stress ulcer prophylaxis claims data in 29,348 commercial and Medicare patients with an acute care hospital admission and subsequent discharge on a PPI determined that $69 \%$ were prescribed a PPI inappropriately at discharge [23].

\section{RECOMMENDATIONS}

Anti-ulcerants will remain to be the first choice of treatment option in patients with upper GI conditions. Although, in most cases, the patients are unaware of the necessity of this drug despite in most cases it was recommended by physicians. It is rudimentary to let know the patients of the duration of intake, side effects of irrational and prolonged use of anti-ulcerants. Follow-up visits should be made obligatory to be aware of the anti-ulcerants consumption rate. The patients should also be taught that it is possible to eliminate the upper GI conditions by maintaining a heathy, controlled and modified life-style. Thorough, organized, cumulative approach can be initiated to address this situation.

\section{LIMITATIONS}

The survey was limited to 103 participants who were admitted in Bangabandhu Sheikh Mujib Medical University (BSMMU). Therefore, the actual scenario of the country as a whole was unable to obtain. Country-wide research can be conducted can be incepted to get to know about the whole situation.

\section{CONCLUSIONS}

Anti-ulcerantshas dramatically changed the treatment difficulties of upper $\mathrm{Gl}$ conditions and helped to alleviate the symptoms thus relieving the patients from disease burden. However, this anti-ulcerants cannot be considered as an unmixed blessing. Through different studies, different adverse effects have been proven due to its prolonged and irrational use. Therefore, a national guideline should be introduced for prescription and medication. Also, a country-wise large, randomized study is needed to be conducted to know the real-time scenario of anti-ulcerants consumptions. Patients should also be taught, not only can anti-ulcerants but also controlled, modified life-style can reduce the symptoms.

\section{Funding}

This research received no specific grant from any funding agency in the public, commercial, or not-for-profit sectors.

Conflict of Interest Statement: The authors declare that there are no conflicts of interest.

\section{REFERENCES}

1. Bardhan, K. D. (1995). The role of proton pump inhibitors in the treatment of gastro-oesophageal reflux disease. Alimentary pharmacology \& therapeutics, 9, 15-25.

2. Sreedharan, A., Martin, J., Leontiadis, G. I., Dorward, S., Howden, C. W., Forman, D., \& Moayyedi, P. (2010). Proton pump inhibitor treatment initiated prior to endoscopic diagnosis in upper gastrointestinal bleeding. Cochrane Database of Systematic Reviews, (7): CD005415.

3. Moayyedi, P., \& Talley, N. J. (2006). Gastro-oesophageal reflux disease. The Lancet, 367(9528), 2086-2100.

4. Leontiadis, G. I., Sharma, V. K., \& Howden, C. W. (2006). Proton pump inhibitor treatment for acute peptic ulcer bleeding. Cochrane Database of Systematic Reviews, (1):CD002094.

5. Leontiadis, G. I., Sreedharan, A., Dorward, S., Barton, P., Delaney, B., Howden, C. W., ... \& Moayyedi, P. (2007). Systematic reviews of the clinical effectiveness and cost-effectiveness of proton pump inhibitors in acute upper gastrointestinal bleeding. In NIHR Health Technology Assessment programme: Executive Summaries. NIHR Journals Library.

6. Huntsberry, A. M., Linnebur, S. A., Fixen, D. R., Saba, L. M., \& Saseen, J. J. (2019). Effects of Chronic Proton-Pump Inhibitor Use on Kidney Function in Older Adults. The Senior care pharmacist, 34(5), 325-333.

7. Marchina, S., Doros, G., Modak, J., Helenius, J., Aycock, D. M., \& Kumar, S. (2019). Acid-suppressive medications and risk of pneumonia in acute stroke patients: A systematic review and meta-analysis. Journal of the neurological sciences, 400, $122-128$.

8. Grunder, F. R., Petit, L. M., Ezri, J., Jantchou, P., Aspirot, A., Laberge, S., \& Faure, C. (2019). Should Proton Pump Inhibitors be Systematically Prescribed in Patients with Esophageal Atresia After Surgical Repair?. Journal of pediatric gastroenterology and nutrition, 69(1), 45-51.

9. Yang, Y. X., Lewis, J. D., Epstein, S., \& Metz, D. C. (2006). Long-term proton pump inhibitor therapy and risk of hip fracture. Jama, 296(24), 2947-2953.

10. Forgacs, I., \& Loganayagam, A. (2008). Overprescribing proton pump inhibitors. BMJ, 336 (7634):2-3.

11. Walker, N. M., \& McDonald, J. (2001). An evaluation of the use of proton pump inhibitors. Pharmacy world and science, 23(3), 116-117.

12. Arafat, S. Y. (2016). Anti-ulcerants: The driving force of the pharma market of Bangladesh. International Journal of Perceptions in Public Health, 1(1), 1-2.

13. Arafat, S. Y., Hasan, M. J., \& Kabir, R. (2017). Use and abuse of anti-ulcerants: A perspective from Bangladesh. International Journal of Research Studies, 1(1), 56-58. 
14. Arafat, S. M. Y., Ahmed, Z., Hasan, M. J., \& Asad, S. M. H. (2016). Medicine promoting marketing factors: Survey among medical representatives in Bangladesh. International Journal of Information Research and Review, 3(5), 2315-2318.

15. Arafat, S. Y., \& Ahmed, Z. (2016). Medical Representative in Bangladesh: a Job with Different Pattern. Int J Acad Res Manag Bus, 1(1):47-51.

16. Arafat, S. Y., Rahman, F. H. S. A. I., \& Al Asad, S. H. (2015). Job Satisfaction Among The Medical Representatives In Bangladesh. Australian journal of business and management research, 5(1), 22-28.

17. Arafat, S. Y., Al, A. S. M. H., Hasan, M. J., Ahmed, Z., Halder, K., \& Rahman, M. I. (2016). Prescription Modifying Marketing Factors: A Survey among the Clinicians in Bangladesh. International Journal of Business and Management Invention, 5(1), 46148.

18. Sostres C, Gargallo CJ, Arroyo MT, Lanas A. Adverse effects of non-steroidal anti-inflammatory drugs (NSAIDs, aspirin and coxibs) on upper gastrointestinal tract. Best practice \& research Clinical gastroenterology. 2010 Apr 1;24(2):121-32.

19. National Health Service. (2006). PACT centre pages. Drugs for dyspepsia. www.ppa.nhs.uk//news/pact-082004.htm.

20. IMS Health Report. (2006). Leading therapy classes by globalpharmaceutical sales. http://www.imshealth.com/ims/portal/front/

21. Arafat, S. Y., \& Andalib, A. (2016). Practicing pattern of physicians in Bangladesh. International Journal of Perceptions in Public Health, 1(1), 9-13.

22. Arafat, S. M. Y. (2016). Doctor patient relationship: an untouched issue in Bangladesh. International Journal of Psychiatry, 1(1), 2.

23. Thomas L, Culley EJ, Gladowski P, Goff V, Fong J, Marche SM. Longitudinal analysis of the costs associated with inpatient initiation and subsequent outpatient continuation of proton pump inhibitor therapy for stress ulcer prophylaxis in a large managed care organization. Journal of managed care pharmacy. 2010 Mar;16(2):122-9. 